\title{
Increased muscle tension and reduced elasticity of affected muscles in recent-onset Graves' disease caused primarily by active muscle contraction
}

\author{
H.J. SIMONSZ \& G. KOMMERELL \\ From the Universitäts-Augenklinik, Freiburg, BRD, the Laboratory of Medical Physics, \\ University of Amsterdam and the Netherlands Ophthalmic Research Institute, Amsterdam, \\ The Netherlands
}

Accepted 18 July 1989

Key words: Graves' disease, eye movements, eye muscles, length-tension measurements

\begin{abstract}
In 3 patients with Graves' disease of recent onset, length-tension diagrams were made during surgery for squint under eyedrop anesthesia. The affected muscles were found to be very stiff when the other eye looked straight ahead. It was expected that these stiff muscles would be able to shorten to some extent but would be unable to lengthen, due to fibrosis of the muscle. We found that the affected muscles did not shorten very much when the other eye looked into the field of action of the muscle. Unexpectedly however, they lengthenend considerably when the other eye looked out of the field of action of the muscle. This finding implies that the raised muscle tension and reduced elasticity of affected muscles in these cases of Graves' disease of recent onset were primarily caused by active muscle contraction, not by fibrosis.
\end{abstract}

\section{Introduction}

The cause of Graves' ophthalmopathy is unknown. It is generally agreed that, after a long period of muscle thickening, fibrosis of the affected muscles occurs, but how this end stage is reached, has remained elusive. Eye muscle thickening, most commonly of medial rectus and inferior rectus muscles, causes protrusion of the eyeballs, restriction of eye movement in the direction opposite to the affected muscle and, in later stages, compression of the optic nerve. Other signs of Graves' ophthalmopathy are retraction of the upper eyelid, periorbital swelling of the skin and squint.

We have made intraoperative, continuous-registration, length-tension diagrams of detached eye muscles in three patients with Graves' disease of recent onset, during surgery for squint under eyedrop anaesthesia, in one patient of both horizontal recti of the left eye, while the other eye looked ahead, right or left, in another patient of the rectus inferior of the right eye, 
while the other eye looked ahead, up or down, and in a third patient of the left medial rectus, while the other eye looked ahead, right or left. We have made these length-tension diagrams of eye muscles in other squint patients also, and one of these is presented here for the sake of comparison.

\section{Patients and methods}

Case 1.. In this 50-year-old female, sixteen months before admission proptosis of the left eye occurred, without sensations of burning or tearing. A CT-scan was made, and a thick medial rectus muscle on the left side was found. In a second CT-scan two months later, thickened medial, superior and inferior rectus muscles were seen on the left side, and a diagnosis of Graves' ophthalmopathy was made. Eight months before admission, corticosteroids and radiation of the left orbit $(20 \mathrm{~Gy})$ were administered, without success. The patient had a small diffuse struma. Thyroid function was normal: Free thyroxin $9.8 \mathrm{ng} / 1$; free tri-iodine-thyronin $4.1 \mathrm{ng} / 1$; TSH (basal): $0.4 \mathrm{mU} / \mathrm{l}$; microsomal antibodies: $39 \mathrm{kU} / 1$; antibodies against thyroglobulin: not demonstrable; TSH-receptor antibodies: $3.8 \mathrm{U} / 1$; free T4: $15 \mathrm{pmol} / 1$; T3: $1.6 \mathrm{nmol} / 1$; iodine phase $2 / 24$ hours: $16 / 55 \%$ of administered dosis. Protein-bound iodine-123 in 24 hour serum: 0.214\%/1. After intravenous administration of $200 \mu \mathrm{g}$ TRH, the TSH level was $0.37,3.06$ and $1.31 \mathrm{mU} / 1$, after 0,25 and 60 minutes, respectively.

The angles of convergent squint were $+10 \mathrm{deg},+7 \mathrm{deg}$ and $+4 \mathrm{deg}$, when the right eye was pointed $25 \mathrm{deg}$ to the left, straight ahead, or $25 \mathrm{deg}$ to the right, respectively. No cyclotropia was present. intraocular pressure rose from 17.5 to $23 \mathrm{~mm} \mathrm{Hg}$ on upgaze, and from 22.5 to $39 \mathrm{~mm} \mathrm{Hg}$ on left-gaze.

Because of decreasing visual acuity $(0.2$, partly caused by keratitis sicca but an afferent pupillary defect was present) and concentric visual field restriction in the left eye, decompression surgery was performed elsewhere, 4 months before admission. The left ethmoid was opened to accommodate part of the contents of the left orbit, including part of the left medial rectus muscle. In addition, the medial orbital floor and the medial wall of the sphenoid were opened. After surgery, the protrusion of the left eye was reduced from 5 to $1 \mathrm{~mm}$, as compared to the right eye, but the convergent squint had increased.

On admission to this hospital, the angles of convergent squint were $+23 \mathrm{deg},+18 \mathrm{deg}$ and $+13 \mathrm{deg}$, when the right eye was pointed $25 \mathrm{deg}$ to the left, straight ahead, or $25 \mathrm{deg}$ to the right, respectively. The surgery for squint consisted of a recession of the insertion of the medial rectus muscle 
by separating it from globe and suturing it back onto the globe $6 \mathrm{~mm}$ behind the old insertion. In addition, the lateral rectus muscle was shortened by a $6 \mathrm{~mm}$ resection. The patient was operated in local anesthesia, i.e. only anesthetic eyedrops (cocain) and subconjunctival injection over the muscle insertion (mepivacain) were used. After surgery, the angles of squint were $+2 \mathrm{deg},-3 \mathrm{deg}$ and $-10 \mathrm{deg}$, respectively. In other words, she now had a divergent squint when looking towards the right.

Case 2.. This 55-year-old man presented 11 months before admission with diplopia of 3 months' duration. He had retraction of upper and lower eyelids. Elevation and abduction were restricted in the right eye. In a CT-scan the inferior muscles were found to be thickened, more pronounced in the right eye. No hyperthyroidism was present, neither anamnestic nor biochemical. Because of progressive complaints of diplopia, the patient was finally admitted to this hospital for surgery. The angles of vertical squint were $1 \mathrm{deg},-4 \mathrm{deg}$ and $-6 \mathrm{deg}$ (negative operation sign indicative of the right eye being lower) when the left eye looked $25 \mathrm{deg}$ to the left, and $25 \mathrm{deg}$ to the right. They were $-6 \mathrm{deg}$ and $-3 \mathrm{deg}$ when the left eye looked $25 \mathrm{deg}$ up or down, respectively. A $2 \mathrm{~mm}$ recession of the right inferior rectus was performed.

Case 3. This 50-year-old woman underwent a subtotal strumectomy for hyperthyroidism 5 months before admission. Substitution therapy was initiated. Apart from hyperthyroidism, she had elevated TSH-receptor autoantibodies, thyroglobulin antibodies and SD microsomal antibodies. There had been marked periorbital oedema since the onset of hypertyroidism. There was some retraction of the upper eyelids. Abduction and elevation were restricted in both eyes. The angles of convergent squint were $9 \mathrm{deg}$, $11 \mathrm{deg}$ and $12 \mathrm{deg}$, when the other eye looked $25 \mathrm{deg}$ to the left, ahead, or $25 \mathrm{deg}$ to the right. A $5 \mathrm{~mm}$ recession of the left medial rectus were performed.

Case 4.. This 60-year-old woman had had vertical diplopia for 20 months. The diplopia had started 5 days after a cerebral infarction. A NMR scan had demonstrated 2 small areas of ischaemia in the left metencephalon and medulla oblongata. A recently made CT-scan did not show thickened eye muscles, although the patient had eyelid retraction and a limitiation of elevation of the right eye. The patient was being treated for hyperthyroidism. One year previously, microsomal antibodies against thyroid tissue were: 1:409600; autoantibodies against TSH receptor: (20\%); FT3-RIA: $14.5 \mathrm{pg} /$ ml; FT4-RIA: $6.2 \mathrm{ng} / \mathrm{dl}$; base TSH: $0.6 \mu \mathrm{E} / \mathrm{ml}$; TSH after TRH stimulation: 
$0.6 \mu \mathrm{E} / \mathrm{ml}$. The patient had been operated and irradiated for uterus carcinoma 5 years previously. The angles of vertical squint were $-12,-7 \mathrm{deg}$ and $-5 \mathrm{deg}$ (negative operation sign indicative of the right eye being lower) when the other eye looked $25 \mathrm{deg}$ up, ahead or down, respectively, the excyclotropia in these directions of gaze being $13 \mathrm{deg}, 7 \mathrm{deg}$ and $7 \mathrm{deg}$, respectively. A recession of the right inferior rectus was performed.

The measurement procedure has been described elsewhere. In short, a length and tension measuring device [6] was fixed during surgery rigidly above the head of the patient. It consisted of a $2 \mathrm{~mm}$ hardened steel shaft, suspended by precision microballbearings and equipped with a shaft-position encoder and an eddy-current motor. The torque generated by the eddy-current motor in the shaft and the position of the shaft were assessed electronically. The frame on which it was mounted consisted of $30 \mathrm{~mm}$ steel posts fixed to the railing of the operating table, a $20 \mathrm{~mm}$ steel traverse bar above the chest of the patient and a $20 \mathrm{~mm}$ steel bar that could be clamped tight in any position rectangular to the traverse bar. The head of the patient was fixed rigidly on the circular cushion of the steel head-support of the operating table. A 4.0 silk suture was passed through the muscle to be measured after it was cut off the globe and wrapped around the shaft with a tight knot. The position of that part of the shaft and the suture were kept in line with the muscle to be measured. The torque generated in the shaft was slowly (taking more than $45 \mathrm{~s}$ either way) increased and decreased, exerting a pull that varied between 0 and $40 \mathrm{~g}$. The measurement was repeated while the patient looked with the other eye maximally into and out of the field of action of the muscle that was measured. The assistant elevated the sterile drape to monitor the position of the other eye. Calibration of the lengthtension measuring device was as described previously [7]. The starting friction of the shaft, due to the precision micro ballbearings, was less than 1 gram.mm. The patients gave oral informed consent.

\section{Results}

In case 1 , the medial rectus muscle was found to be very stiff when the right eye looked straight ahead (Fig. 1a). The medial rectus did not shorten any further when the right eye looked far to the right. Unexpectedly, however, the affected muscle lengthenend considerably when the right eye looked far to the left. It must be noted, however, that in the first measurement, the position of the head was not monitored as closely as it was later on. Therefore, a small turn of the head may have accompanied left and right gaze. Only when the patient looked to the left with the right eye, the pull 


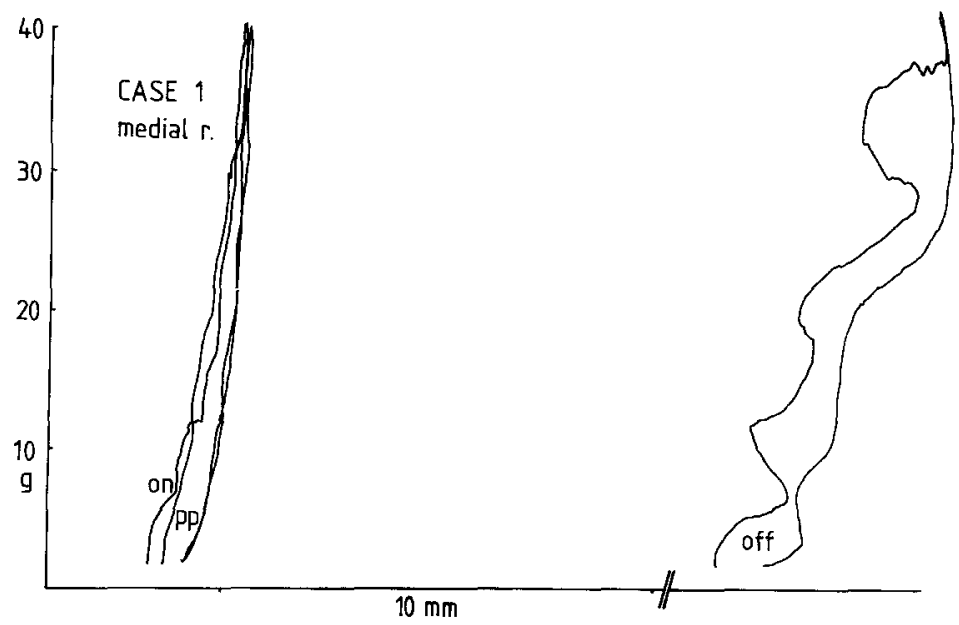

Fig. Ia. Case 1, medial rectus muscle. The muscle was found to be very stiff when the right eye looked straight ahead (pp). The medial rectus did not shorten any further when the right eye looked far to the right (on). Unexpectedly, however, the affected muscle lengthened considerably when the right eye looked far to the left (off). It must be noted, however, that in the first measurement, the position of the head was not monitored as closely as it was later on. Therefore, a small turn of the head may have accompanied left and right gaze. For this reason the abscissa is interrupted. The curved nature of the off-registration is caused by unsteadiness of gaze holding.

exerted on the extended medial rectus muscle was painful from approximately $15 \mathrm{~g}$ onward. Pull exerted on the muscle was not painful when the patient looked straight ahead or to the right. In all other patients, pain was

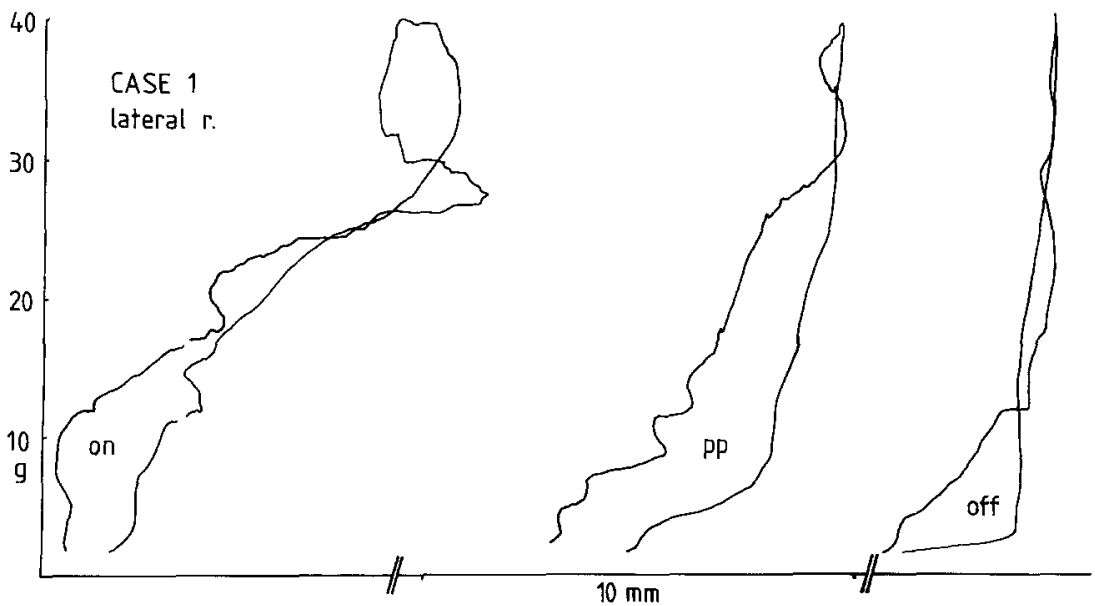

Fig. $1 b$. The length-tension characteristics of the antagonist lateral rectus muscle were more normal. A considerable shortening was possible from primary position length. In addition the muscle was less stiff in the contracted state, which is the normal situation. 


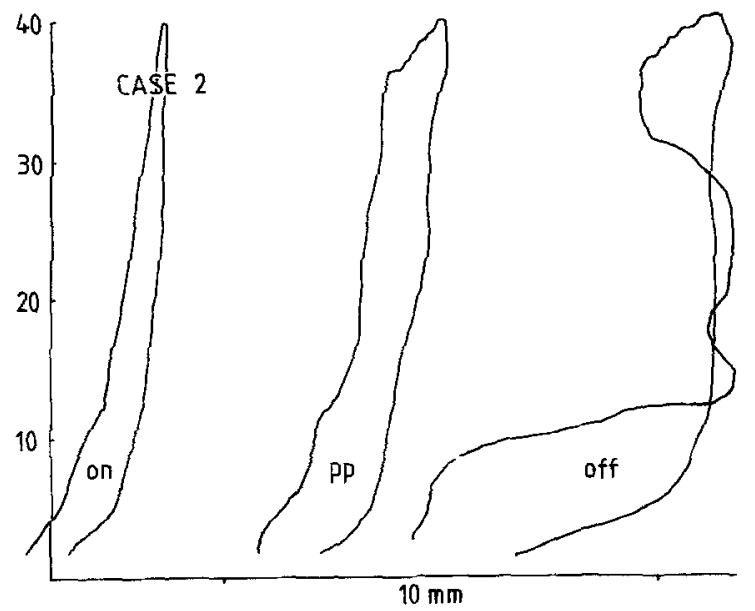

Fig. 2. Case 2, inferior rectus muscle. The length-tension characteristics of the affected inferior rectus were essentially the same as in case 1 , although some shortening $(5 \mathrm{~mm})$ occurred when the other eye looked into the field of action of the affected muscle. The lengthening out of primary-position length $(7 \mathrm{~mm})$ was, however, greater than the shortening.

never experienced during pull, with forces varying between 0 and $40 \mathrm{~g}$. The length-tension characteristics of the antagonist lateral rectus muscle were more normal (Fig. 1b). A considerable shortening was possible from primary position length. In addition the muscle was less stiff in the contracted

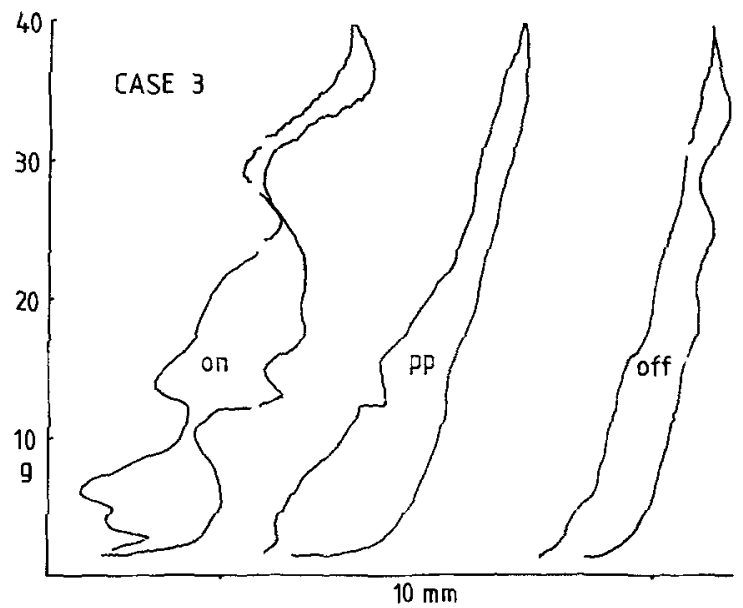

Fig. 3. Case 3, medial rectus muscle. The medial rectus shortened by approximately $4 \mathrm{~mm}$ out of primary-position length when the other eye looked into the field of action of the affected muscle, and lengthened by $5 \mathrm{~mm}$ when the other eye looked out of the field of action of the affected muscle. The increased stiffness of the muscle was approximately the same in both the shortened and the extended conditions. 


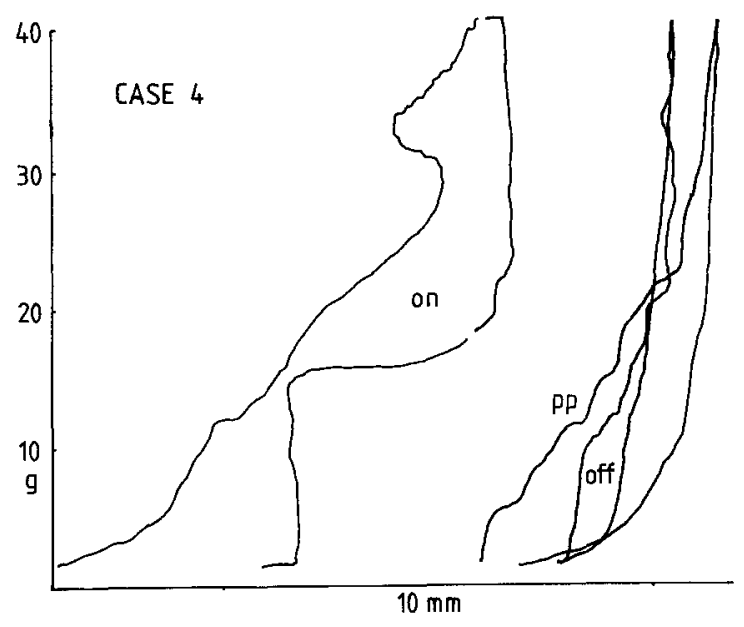

Fig. 4. Case 4 (no Graves' disease), inferior rectus muscle. The length-tension characteristics of the inferior rectus muscle were very unlike the findings in cases $1-3$, and much more like those found in patients with other kinds of squint: the base tension of the muscle (other eye in primary position) was slightly more than that in the fully relaxed muscle, and considerable shortening was possible. It should be noted, however, that the curves found for relaxed muscle and for looking ahead are so similar, that some kind of muscle weakness may be surmised. Experience in the interpretation of length-tension diagrams however, is at present too limited to warrant further conclusions.

state, which is the normal situation.

In case 2 , the length-tension characteristics of the affected inferior rectus were essentially the same as in case 1 , although some shortening $(5 \mathrm{~mm})$ occurred when the other eye looked into the field of action of the affected muscle. The lengthening out of primary-position length $(7 \mathrm{~mm})$ was, however, greater than the shortening (Fig. 2).

In case 3 , the medial rectus shortened by approximately $4 \mathrm{~mm}$ out of primary-position length when the other eye looked into the field of action of the affected muscle, and lengthened by $5 \mathrm{~mm}$ when the other eye looked out of the field of action of the affected muscle. The stiffness of the muscle was approximately the same in shortened and extended condition (Fig. 3).

In case 4 (no Graves' disease) the length-tension characteristics of the inferior rectus muscle were very unlike the findings in cases $1-3$, and much more like those found in patients with other kinds of squint: the base tension of the muscle (other eye in primary position) was slightly more than that in the fully relaxed muscle, and considerable shortening was possible. It should be noted, however, that the curves found for relaxed muscle and for looking ahead are so similar, that some kind of muscle weakness may be surmised. Experience with the interpretation of length-tension diagrams, however, is at present too limited to warrant further conclusions (Fig. 4). 


\section{Discussion}

The finding of a very stiff muscle when the other eye looked ahead, little additional contraction when the other eye looked into the field of action of the muscle, but considerable relaxation when the other eye looked out of the field of actin of the muscle, indicates that the level of innvervation to the affected muscle was high when the other eye looked ahead, and that the increased muscle tension and reduced elasticity of the affected muscle in these cases of Graves' disease of recent onset were caused by active muscle contraction, not by fibrosis. This is not meant to imply that fibrosis plays no major role in Graves' disease: On the contrary, fibrosis of the affected muscles is the end-stage of the disease. But the fact that the muscles were contracting powerfully, when the other eye looked ahead, and could lengthen when the other eye looked out of the field of action of the muscle, indicates that in these cases the increased tension (manifesting itself as strabismus) and the increased elasticity were caused by active muscle contraction.

What could cause this high level of contraction? It has been found previously that hyperthyroidism, induced in rats, causes a transition to faster myosin-heavy-chain (MHC) types [3,9]. In human skeletal muscles, MHC types are expressed successively during embryonal, neonatal and juvenile development [1]; in other words, as new MHC types appear, previous MHC types, like embryonal and neonatal MHC, disappear. In human eye muscles, however, almost all MHC types coexist [9]: they contain fast and slow, but also embryonal and neonatal, MHC. They are also the only human muscles that have slow-tonic, multiply innervated muscle fibers. The fact that hyperthryoidism causes a transition to faster MHC types in rats raises the following intriguing question: Was the increased level of contraction of the affected muscles in our patients with Graves' disease of recent onset caused by a transition from slow to fast muscle fiber types? The innervation of the slow muscle fibers is likely to be almost continuous, to abate only in extreme gaze out of the field of action of the muscle [2]. It seems conceivable that fibers that underwent a transition to a faster type would contract powerfully when stimulated by this continuous-type innervation.

There is additional evidence to support this speculation. Firstly, we have previously made length-tension registrations in patients with Graves' disease during general anaesthesia for squint surgery. In these patients we found no contraction of the affected eye muscles afer administration of succinylcholine chloride, that normally causes an intense contraction of eye muscles by stimulating the slow-tonic multiply innervated muscle fibers [8]. The lack 
of contraction could be interpreted as a loss of slow fibers, which would be compatible with a transition from slow to faster fiber types.

Secondly, one would expect saccadic peak velocity to increase if a transition to a faster fiber type had taken place. This has indeed been found: Kirsch et al. [4] found saccadic peak velocities of 800 to $900 \mathrm{deg} / \mathrm{s}$ in Graves' disease of recent onset, in one patient more than $1000 \mathrm{deg} / \mathrm{s}$. Other symptoms in Graves' disease, like fatigability of leg muscles (climbing stairs, for instance) could also be related to transitions of MHC heavy chain types.

In accord with the concept of active muscle contraction, it has been found that only recent-onset cases of Graves' react favorably to botulinum toxin [5]. Botulinum toxin causes a muscle paralysis lasting approximately three months (with a wide spread). The release of the contracture takes place within two weeks after injection of botulinum, which seems too short a period for release of a connective-tissue fibrosis and points to the contracture being caused by active muscle contraction.

This elevated level of contraction could secondarily lead to hypertrophy of the muscle. The thickness of the muscle, as found in CT-scanning, has been found to correlate with the limitation of movement of the eye out of the field of action of the muscle (M. Mourits, personal communication, Amsterdam, February 9th, 1989).

Our finding must be interpreted with great care, however, because several phenomena remain unexplained in our hypothesis: The ocular symptoms may occur years after the onset of hyperthyroidism but also before its onset. Moreover, eye muscle thickening never regresses fully when the throid status of the patient is normalized.

\section{Acknowledgement}

This work was supported by a fellowship from the Royal Netherlands Academy of Arts and Sciences to H.J. Simonsz.

\section{References}

1. Caplan AI, Fiszman MY, Eppenberger HM. Molecular and cell isoforms during development. Science 1983; 221: 921-7.

2. Gornig H, Asmussen G, Kiessling A. Vorkommen und Bedeutung monophasischer Potentiale im Elektromyogramm der ausserer Augenmuskeln von Kaninchen und Katze. Graefes Arch Clin Exp Ophthalmol 1975; 196: 159-67.

3. Izumo S, Nadal-Ginard B, Mahdavi V. All members of the MHC multigene family respond to thyroid hormone in a highly tissue-specific manner. Science $1986 ; 226: 597-600$.

4. Kirsch A, Konen W, Rüssmann W. Vertikale Sakkaden bei endokriner Orbitopathie. First 
Symp Bielschowsky-Gesellschaft für Schielforschung, Göttingen, October 4-5, 1986.

5. Roggenkämper P. Die Anwendung von Botulinum Toxin zur Behandlung des Strabismus. In: Orthoptik-Pleioptik, ed. Lenk-Schäfer M. (in print) Berufsverband der Orthoptistinnen Deutschlands, Nürnberg, 1989.

6. Simonsz HJ, Crone RA, de Waal BJ, Schooneman M, Lorentz de Haas HAL. Measurement of the mechanical stiffness in cyclotorsion of the human eye. Vision Res 1984; 24 : 961-8.

7. Simonsz HJ, Kolling GH, Kaufmann H, van Dijk B. Intraoperative length and tension curves of human eye muscles and stiffness in passive horizontal eye movement in awake volunteers. Arch Ophthalmol 1986; 104: 1495-1500.

8. Simonsz HJ, Kolling GH, Kaufmann H, van Dijk B. Length-tension curves of human eye muscles during succinylcholine-induced contraction. Invest Ophthalmol 1988; 29: 1320-31.

9. Wieczorek DF, Periasamy M, Butler-Browne S, Whalen RG, Nadal-Ginard B. Coexpression of multiple myosin heavy chain genes, in addition to a tissue-specific one, in extraocular musculature. J Cell Biol 1985; 101: 618-29.

Address for correspondence: H.J. Simonsz, Netherlands Ophthalmic Research Inst., P.O. Box 12141, 1100 AC Amsterdam. 